\title{
Commentary
}

\author{
HORMONE \\ RESEARCH IN \\ PAEDIATRICS
}

\section{HMGB1: A Possible Crucial Therapeutic Target for COVID-19?}

\author{
Maria Elisabeth Street \\ Division of Paediatric Endocrinology and Diabetology and Research Laboratory, Department of Mother and Child, \\ Paediatrics, AUSL-IRCCS di Reggio Emilia, Reggio Emilia, Italy
}

Since COVID-19 is a global health emergency, any hypothesis that can explain the course and complications of this disease, and lead to a more focused treatment and self-limiting progression of the infection, should be put forward. A whole series of symptoms and features related to this disease have emerged from reports including fever, cough, myalgia, sore throat, dyspnea, headache, lymphopenia, and acute respiratory distress syndrome (ARDS), but also acute cardiac and kidney injury, secondary infection, shock [1], vasculitis, thrombosis, and disseminated intravascular coagulation. In some patients, significant levels of antiphospholipid antibodies have been found [2], which, in association with extremely elevated proinflammatory cytokines, are probably responsible for the worst course and outcome, and have led to the current ongoing trials on biological drugs against IL-1 receptor, IL-6, and IL-6 receptor, among others [3]. Fibrosis is present in the lungs of severely affected patients [4]. Amyloidosis and thrombosis have been reported by colleagues as present in autoptic specimens but have not yet been reported in the literature.

Patients with obesity are at an increased risk of developing COVID-19 $[5,6]$, possibly aggravated further by the presence of nonalcoholic fatty liver disease [6]. Obe- sity is also characterized by low-grade chronic inflammation.

High mobility group box-1 (HMGB1) is a chromatinlinked, nonhistomic, small protein with cytokine activity that has nuclear, cytosolic, and extracellular actions. It binds to chromosomal DNA but also to Toll-like receptor 3 (TLR3), TLR4, and the receptor for advanced glycation end products (RAGE) that activates nuclear factor (NF)$\kappa B$ (Fig. 1a), which mediate the upregulation of leukocyte adhesion molecules as well as the production of proinflammatory cytokines and angiogenic factors that promote inflammation. HMGB1 was initially known as alarmin and is a well-recognized damage-associated molecular pattern (DAMP) protein.

HMGB1 has been extensively studied within the field of endocrinology as it is clearly involved with obesity [7], insulin resistance, and diabetes [8], and more recently polycystic ovary disease [9], another condition characterized by low-grade chronic inflammation (Fig. 1b).

Interestingly, it has been recognized that HMGB1 regulates autophagy [10] and could potentially be a biomarker of acute lung injury [11]. Autophagy is one of the mechanisms involved in COVID-19 and is involved in viral entry and replication in cells, so targeting this pro-

\section{KARGER}

(c) 2020 S. Karger AG, Basel

karger@karger.com

www.karger.com/hrp
Maria E. Street, $\mathrm{MD}, \mathrm{PhD}$

Division of Paediatric Endocrinology and Diabetology and Research Laboratory Department of Mother and Child, Paediatrics

AUSL-IRCCS di Reggio Emilia, Viale Risorgimento 80, IT-42123 Reggio Emilia (Italy) mariaelisabeth.street@ausl.re.it 


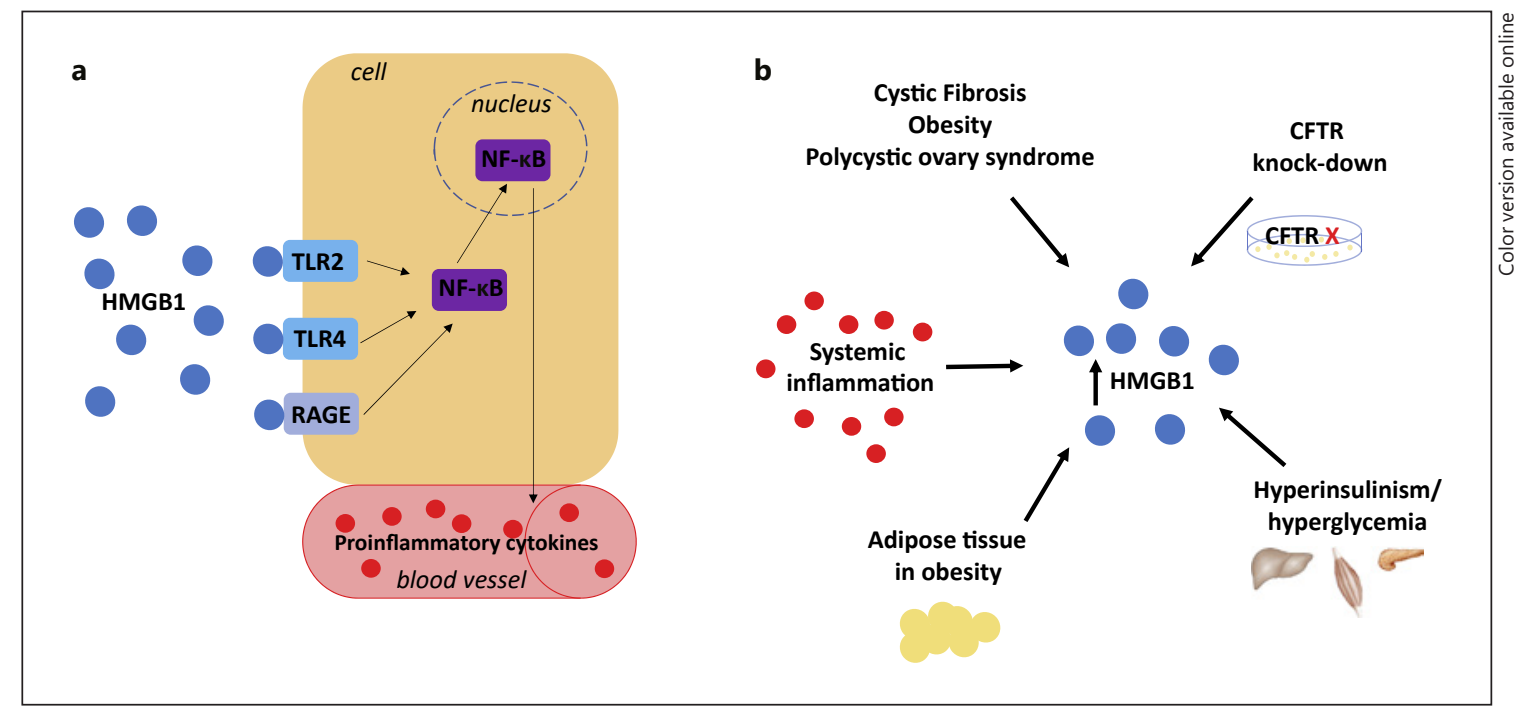

Fig. 1. a HMGB1 shows both intracellular and extracellular effects. By binding to TLR2, TLR4, and RAGE, it activates NF- $\mathrm{BB}$ which leads to the production of proinflammatory cytokines that have local and systemic effects. b HMGB1 is increased both locally and in the circulation in conditions like obesity, cystic fibrosis, and polycystic ovary, and, whenever insulin resistance occurs, it is produced by adipose tissue and the immune system. CFTR malfunction causes an increase in HMGB1, besides other changes such as inflammation and increased autophagy.

cess has been suggested as a possible novel therapeutic strategy for COVID-19 [12].

Furthermore, HMGB1 expression is increased in thrombosis-related diseases $[13,14]$, and has been studied in alveolar epithelial cells [14]. Finally, HMGB1, via RAGE, mediates sepsis-triggered amyloid- $\beta$ accumulation in diseases of the central nervous system associated with impaired cognitive function, e.g., neurodegenerative diseases [15].

Most interestingly, HMGB1 gene polymorphisms are associated with hypertension in the Han Chinese population [16], which also suggests that it could be implicated in the outcome and course of COVID-19 in some individuals.

It is now well known that SARS-CoV2 requires angiotensin-converting enzyme (ACE) II receptors for viral entry and replication [17]. Kuba et al. [18] showed in mice that SARS-CoV downregulated ACE II protein, contributing to severe lung injury. Interestingly, ACE II overexpression has been reported to reduce HMGB1, besides reducing apoptosis in the myocardium postinfarction, in a rat model [19]. This leads to the hypothesis that a reduction in ACE II induced by the virus would in turn increase HMGB1, thus contributing to the "cytokine storm" and the worst scenarios seen with COVID-19 infection.
The inflammasome mediates HMGB1 translocation from the nucleus to the cytoplasm, with subsequent release from the cell via type 1 interferon JAK/STAT1 activation. Thus, pharmacological inhibition of JAK/STAT1 could be an approach for reducing circulating HMGB1 [20]. HMGB1 is recognized as a drug target, in particular for the salicylic acid (SA) derivatives 3-aminoethyl SA and amorfrutin B1, and methotrexate, inflachromene, and glycyrrhizin have also been shown to lower HMGB1 [21]. In 2003, in an in vitro model, a German group used glycyrrhizin to inhibit the replication of SARS-CoV1, the virus that was circulating at that time, and described this compound as effective as ribavirin and mycophenolic acid, and more effective than 6-azauridine and pyrazofurin. This finding was confirmed in vitro using serum samples from patients, but the mechanism of action remained unclear [22].

In addition to these considerations, in 2004, it was hypothesized that HMGB1 could play a possible pathogenic role in SARS-Cov1 [23].

Finally, my research group previously showed that cystic fibrosis transductance regulator (CFTR) malfunction, as found in cystic fibrosis, increases HMGB1 serum concentrations, along with inflammation, and further increases are observed at the onset of the specifically related diabetes [24]. This suggests that changes in CFTR expres- 
sion and/or specific polymorphisms could play a role, particularly in the lung, and some of the new CFTR modulators should be considered for treatment if this were indeed the case $[25,26]$. Furthermore, diabetes is a recognized risk factor for Sars-CoV2 infection [27], and HMGB1 is known to be increased in diabetes [8].

In conclusion, I support the need for assaying HMGB1 in the serum samples of COVID-19 patients who have been affected differently and are thus currently receiving different treatment. This would clarify whether HMGB1 could be a marker of poor prognosis and a potential target for treatment. Furthermore, could the HMGB1 gene polymorphisms explain some of the variations observed in these patients? If so, this should be addressed and integrated into treatment.

Should we now be considering add-on treatment with drugs like glycyrrhizin, that reduce HMGB1, and then rapidly hypothesize the dose and mode of administration?

\section{Disclosure Statement}

I declare there are no competing interests.

\section{References}

1 Rodriguez-Morales AJ, Cardona-Ospina JA, Gutierrez-Ocampo E, et al. Clinical, laboratory and imaging features of COVID-19: A systematic review and meta-analysis. Travel Med Infect Dis. 2020. DOI: 10.1016/j. tmaid.2020.101623.

2 Zhang Y, Xiao M, Zhang S, Xia P, Cao W, Jiang $\mathrm{W}$, et al. Coagulopathy and antiphospholipid antibodies in patients with Covid-19. N Engl J Med. 2020;382(17):e38.

3 Favalli EG, Ingegnoli F, De Lucia O, Cincinelli G, Cimaz R, Caporali R. COVID-19 infection and rheumatoid arthritis: Faraway, so close! Autoimmun Rev. 2020 May; 19(5): 102523.

4 Dai H, Zhang X, Xia J, et al. High-resolution chest $\mathrm{CT}$ features and clinical characteristics of patients infected with Covid-19 in Jiangsu, China. Int J Infect Dis. 2020 Apr;95:106-12.

5 Sattar N, McInnes IB, McMurray JJV. Obesity a risk factor for severe COVID-19 Infection: multiple potential mechanisms. Circulation. 2020. DOI: $10.1161 /$ CIRCULATIONAHA. 120.047659 .

6 Zheng KI, Gao F, Wang XB, Sun QF, Pan KH, Wang TY, et al. Obesity as a risk factor for greater severity of COVID-19 in patients with metabolic associated fatty liver disease. Metabolism. 2020. DOI: 10.1016/j.metabol.2020.154244.

7 Zhang J, Zhang L, Zhang S, Yu Q, Xiong F, Huang K, et al. HMGB1, an innate alarmin, plays a critical role in chronic inflammation of adipose tissue in obesity. Mol Cell Endocrinol. 2017 Oct;454:103-11.

8 Biscetti F, Rando MM, Nardella E, et al. High mobility group box-1 and diabetes mellitus complications: state of the art and future perspectives. Int J Mol Sci. 2019;20(24):pii: E6258.

9 Cirillo F, Catellani C, Sartori C, Lazzeroni P, Morini D, Nicoli A, et al. CFTR and FOXO1 gene expression are reduced and high mobility group box 1 (HMGB1) is increased in the ovaries and serum of women with polycystic ovarian syndrome. Gynecol Endocrinol. 2019;10:1-5.
10 Sun X, Tang D. HMGB1-dependent and -independent autophagy. Autophagy. 2014 Oct; 10:1873-6.

11 Qu L, Chen C, Chen Y, Li Y, Tang F, Huang $\mathrm{H}$, et al. High-Mobility Group Box 1 (HMGB1) and autophagy in acute lung injury (ALI): a review. Med Sci Monit. 2019 Mar;25:182837.

12 Yang N, Shen HM. Targeting the endocytic pathway and autophagy process as a novel therapeutic strategy in covid-19. Int J Biol Sci. 2020 Mar; 16(10):1724-31.

13 Cai J, Yuan H, Wang Q, Yang H, Al-Abed Y, Hua Z, et al. HMGB1-driven inflammation and intimal hyperplasia after arterial injury involves cell-specific actions mediated by TLR4. Arterioscler Thromb Vasc Biol. 2015 Dec;35(12):2579-93.

14 Pittet JF, Koh H, Fang X, Iles K, Christiaans S, Anjun N, et al. HMGB1 accelerates alveolar epithelial repair via an IL- $1 \beta$ - and $\alpha v \beta 6$ integrin-dependent activation of TGF- $\beta 1$. PLoS One. 2013 May;8(5):e63907.

15 Gasparotto J, Girardi CS, Somensi N, Ribeiro CT, Moreira JC, Michels M, et al. Receptor for advanced glycation end products mediates sepsis-triggered amyloid- $\beta$ accumulation, Tau phosphorylation, and cognitive impairment. J Biol Chem. 2018 Jan;293(1):226-44.

16 Yao Y, Guo D, Yang S, Jin Y, He L, Chen J, et al. HMGB1 gene polymorphism is associated with hypertension in Han Chinese population. Clin Exp Hypertens. 2015;37(2):166-71.

17 Zhang H, Penninger JM, Li Y, Zhong N, Slutsky AS. Angiotensin-converting enzyme 2 (ACE2) as a SARS-CoV-2 receptor: molecular mechanisms and potential therapeutic target. Intensive Care Med. 2020 Apr;46(4):58690.

18 Kuba K, Imai Y, Rao S, Gao H, Guo F, Guan $\mathrm{B}$, et al. A crucial role of angiotensin converting enzyme 2 (ACE2) in SARS coronavirusinduced lung injury. Nat Med. 2005 Aug; 11(8):875-9.
19 Qi YF, Zhang J, Wang L, Shenoy V, Krause E, Oh SP, et al. Angiotensin-converting enzyme 2 inhibits high-mobility group box 1 and attenuates cardiac dysfunction post-myocardial ischemia. J Mol Med (Berl). 2016 Jan;94(1): 37-49.

20 Lu B, Antoine DJ, Kwan K, Lundbäck P, Wähämaa $\mathrm{H}$, Schierbeck $\mathrm{H}$, et al. JAK/STAT1 signaling promotes HMGB1 hyperacetylation and nuclear translocation. Proc Natl Acad Sci USA. 2014 Feb;111(8):3068-73.

21 Venereau E, De Leo F, Mezzapelle R, Careccia G, Musco G, Bianchi ME. HMGB1 as biomarker and drug target. Pharmacol Res. 2016 Sep;111:534-44.

22 Cinatl J, Morgenstern B, Bauer G, Chandra P, Rabenau H, Doerr HW. Glycyrrhizin, an active component of liquorice roots, and replication of SARS-associated coronavirus. Lancet. 2003 Jun;361(9374):2045-6.

23 Chen G, Chen DZ, Li J, Czura CJ, Tracey KJ, Sama AE, et al. Pathogenic role of HMGB1 in SARS? Med Hypotheses. 2004;63(4):691-5.

24 Montanini L, Cirillo F, Smerieri A, Pisi G, Giardino I, d'Apolito M, et al. HMGB1 is increased by CFTR loss of function, is lowered by insulin, and increases in vivo at onset of CFRD. J Clin Endocrinol Metab. 2016 Mar; 101(3):1274-81.

25 Ghelani DP, Schneider-Futschik EK. Emerging cystic fibrosis transmembrane conductance regulator modulators as new drugs for cystic fibrosis: a portrait of in vitro pharmacology and clinical translation. ACS Pharmacol Transl Sci. 2020;3:4-10.

26 Ridley K, Condren M.Elexacaftor-TezacaftorIvacaftor: the First triple-combination cystic fibrosis transmembrane conductance regulator modulating therapy. J Pediatr Pharmacol Ther. 2020;25(3):192-7.

27 Guo W, Li M, Dong Y, Zhou H, Zhang Z, Tian $\mathrm{C}$, et al. Diabetes is a risk factor for the progression and prognosis of COVID-19. Diabetes Metab Res Rev. 2020. DOI: 10.1002/ dmrr.3319. 